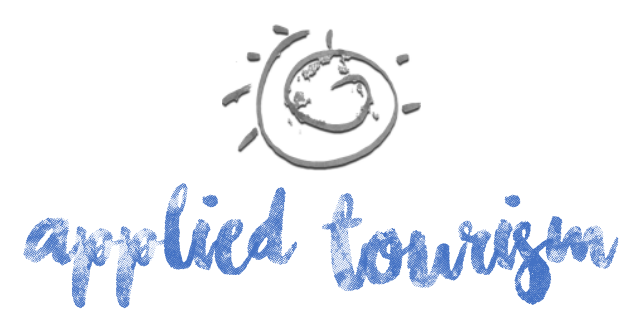

Volume 2, número 2, 2017, p. 56-77

\title{
ANÁLISE TÉCNICO-CIENTÍFICA PARA REFORMULAÇÃO ESTRUTURAL DO PROGRAMA PÃO ESCOLA
}

\author{
Frederico Divino Dias \\ Mestre Em Gestão Social, Educação E Desenvolvimento Local \\ Faculdade Promove de Belo Horizonte (Belo Horizonte, MG) \\ frederico.dias@faculdadepromove.br \\ Frederico de Carvalho Figueiredo \\ Doutor em Gestão Urbana \\ Centro Universitário UNA (Belo Horizonte, MG) \\ frederico.figueiredo@prof.una.br
}

Recebido: 28 de junho, 2017

Aprovado: 04 de setembro, 2017

\section{RESUMO}

Este artigo tem como base temática as políticas de educação profissional. Dentro deste estudo resgata-se de forma sucinta os resultados obtidos na pesquisa "Educação Profissional e Empoderamento: um estudo do Programa Pão Escola da Prefeitura de Belo Horizonte" realizada com o objetivo de avaliar o referido Programa quanto ao seu potencial de estimular os alunos a entrarem no processo de empoderamento individual. Evidenciam-se conceitos-chave tais como a interdisciplinaridade, a intersetorialidade e as legislações educacionais vigentes na sociedade atual. Tais conceitos foram apresentados para assistirem teoricamente o produto desenvolvido. Apresentou-se uma proposta inovadora a ser exposta para o executivo municipal: uma nova portaria para regulamentar o Programa. Finaliza-se resgatando os objetivos explicitados anteriormente e apontando novos estudos necessários na área.

Palavras-chaves: Educação Profissional. Empoderamento. Desenvolvimento Local. Parecer técnico-científico. Portaria Municipal. 


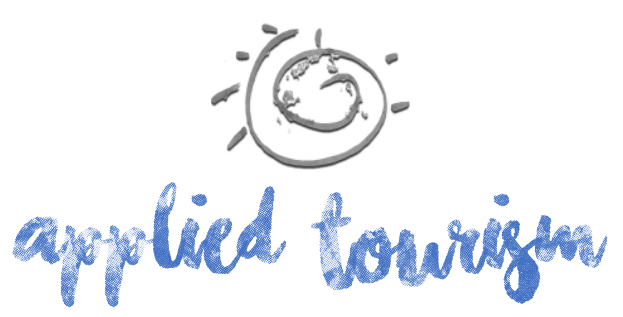

Volume 2, número 2, 2017, p. 56-77

A partir da análise destes dados este artigo apresenta uma proposta de intervenção no PPE. Tal proposição baseia-se na apresentação de uma proposta de readequação da portaria municipal que regulamenta o Programa em questão objetivando torná-lo uma ferramenta que desperte o potencial humano dos sujeitos e incentive-os a entrarem no processo de empoderamento individual.

Tal proposta pauta-se em estudos que apresentam conceitos chave para a mudança das realidades observadas atualmente. Os conceitos de interdisciplinaridade, intersetorialidade e empoderamento, complementaram-se para, juntamente com as legislações pertinentes, oferecer uma proposta inovadora que afeta toda a dinâmica do Programa em vistas de valorizar os sujeitos e formá-los com cada vez mais qualidade e efetividade humana.

Objetivando apresentar uma nova formulação aos moldes do PPE, o presente estudo traz como objetivo específico levantar conceitos pertinentes às áreas que envolvam a educação, apresentar a dinâmica legal no que se refere às políticas educacionais, além de evidenciar as relações entre os discursos dos diversos autores trazidos ao longo do trabalho justificando-se assim as intervenções propostas. Espera-se com estes produtos, fomentar o potencial do Programa para torná-lo referência no que diz respeito a uma formação profissional empoderadora.

\section{REFERENCIAL TEÓRICO}

\section{Interdisciplinaridade}

Os estudos de Assumpção (1991) mostram que a decomposição do termo explicita a noção de interação recíproca entre disciplinas, ou seja, a interdisciplinaridade é vista como um constante movimento de disciplinas no qual todas elas relacionam-se de forma real e participativa em prol de determinado impacto final. De acordo com Thiesen (2008) há um foco comum de que a interdisciplinaridade busca superar a visão subdividida nos processos 


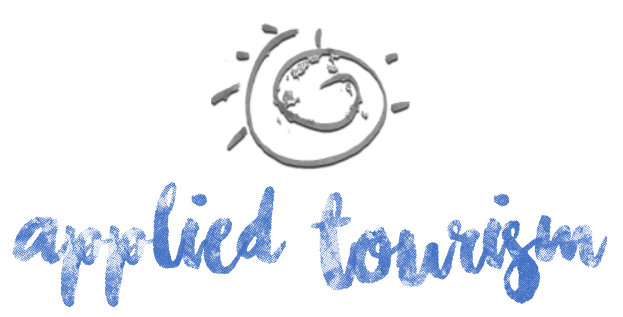

Volume 2, número 2, 2017, p. 56-77

de produção do conhecimento: é um novo meio de produção acadêmica, de formação do conhecimento e/ou transferência do mesmo.

A proposta interdisciplinar, como afirmam Azevedo \& Andrade (2007), promoveria uma nova relação entre professor-aluno percorrendo uma interação entre os sujeitos-sociedadeconhecimentos. A escola a partir disto seria mais dinâmica, interativa e viva; nela os conteúdos seriam problematizados em várias disciplinas e não seriam mais vistos como fatos isolados, localizados e pertencentes a apenas determinado campo de estudo. Tal proposta emerge como a interação do conhecimento que "vem buscando romper com o caráter de hiperespecialização e com a fragmentação dos saberes" (Thiesen, 2008, p. 546).

Para tal, faz-se necessário o rompimento com os limites do conhecimento; é fundamental também, a apropriação de uma atitude e postura interdisciplinar por parte dos profissionais da educação. Essa postura será manifestada no compromisso do educador, na busca de aprofundamento, na sua postura ética e no envolvimento com projetos em sua área de atuação de acordo com os escritos de Thiesen (2008). O professor deixará de ser um transmissor de conteúdo, ele será um pesquisador, um incentivador que possibilitará aos alunos a vivência e a prática da pesquisa. A partir da problematização de situações e a reconstrução de conhecimentos, o aluno teria capacidade de formar novos arranjos de relações nas diversas áreas da ciência, o que consequentemente torná-lo-ia autônomo diante da autoridade do saber (Azevedo \& Andrade, 2007).

Ambicionando trabalhar em uma perspectiva mais emancipadora, surgem atualmente algumas novas metodologias de aprendizagem para facilitar o processo de assimilação do conteúdo por parte dos discentes. Como visto que, por meio da interdisciplinaridade, os processos de aprendizado superariam a transmissão linear, Barbosa \& Moura (2013), Ottonelli, Viero \&Rocha (2015) e Weinberg (2014) apresentam em suas obras algumas metodologias - ferramentas - para propiciar um melhor ambiente acadêmico. Os autores indicam alguns recursos que vem sendo utilizados atualmente e, além de formar o 


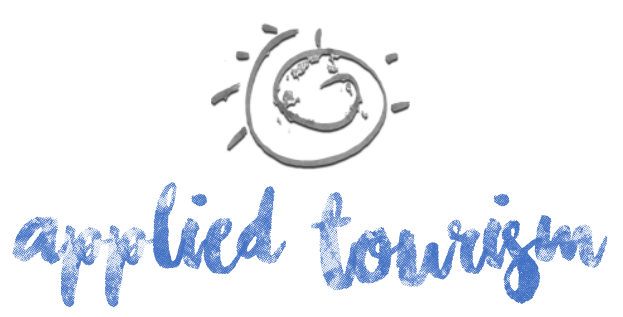

Volume 2, número 2, 2017, p. 56-77

Visto que a intersetorialidade necessita da criação e articulação efetiva de uma rede, Junqueira (1999 apud Comerlato et. al. 2007), nos reafirma a importância desta associação; ele aponta que através dela seriam descobertos novos caminhos para a ação de intervenção na realidade social; os diversos saberes e experiências articulados através deste conjunto de relações, atuariam eficazmente cumprindo o objetivo estabelecido pela proposta inicial da ação.

Inojosa (2001) afirma ainda que em muitos projetos vê-se a proposta intersetorial como a associação de entidades que estabelecem diálogo apenas nos momentos de formulação e avaliação, o que não pode ser considerado como uma ação integrada de criação de rede. Fala-se de uma perspectiva muita mais ampla, há a necessidade da associação com a troca recíproca entre os atores. Ela aponta dois aspectos fundamentais para a formulação, realização e avaliação de tais projetos e/ou políticas e programas: o foco em determinado segmento da população; e a preocupação com os resultados e impactos.

Entende-se, finalmente, que a proposta intersetorial, envolve diversos saberes, conhecimentos, estruturas de linguagens, pensamentos ora convergentes, ora divergentes, e comunicação dentro da rede e outras práticas dos atores. É um processo novo de planejar, implantar, acompanhar e avaliar ações, que integradas, verdadeiramente associadas, cobraria dos sujeitos e instituições um reordenamento de posturas e manifestações, segundo Comerlatto et. al. (2007). Trata-se, portanto, de um olhar e de um fazer intersetoriais que, traçados pelas necessidades integradas da população, impulsionaria novos diálogos e mudanças futuras (Inojosa, 2001).

\section{Normativas da educação e a EP}

Para o cabal desenvolvimento da proposta referente a esta pesquisa, fez-se necessário levantar os princípios básicos pertinentes à educação, normatizados por meio da Lei de Diretrizes e Bases da Educação Nacional (LDB) e outros documentos no que concerne à 


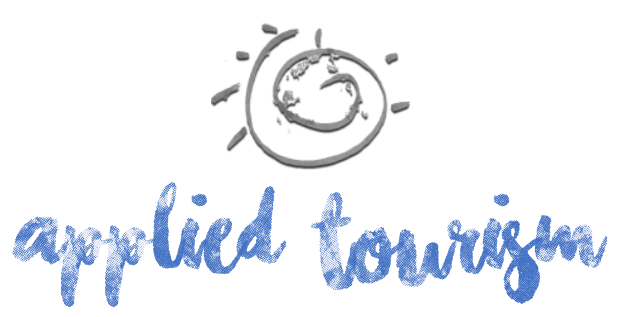

Volume 2, número 2, 2017, p. 56-77

(2012), Frigotto (2013), Figueiredo \& Mueller (2015), Schlesener (2015) e Dias, Machado \& Figueiredo (2016).

\section{METODOLOGIA}

O presente artigo baseou-se em um levantamento bibliográfico e análise dos dados finais da pesquisa do PPE realizada anteriormente para que fosse estruturada uma nova proposta de formatação do Programa. Baseando-se no método dedutivo e de caráter explicativo, este texto objetivou expor de forma clara as razões das propostas de alteração e inovação na portaria municipal que regulamenta o Programa.

A proposição de uma nova portaria foi fundamentada nos princípios básicos da educação trazidos por meio das leis apresentadas na seção anterior além dos teóricos que apresentam as discussões sobre a interdisciplinaridade, intersetorialidade, desenvolvimento local e empoderamento. Baseada no manual da Presidência da República, tal orientação valeu-se da normativa principal da nação - além das demais expostas na seção anterior - para, com base nos teóricos apresentados, propor uma intervenção que respeite o que é normatizado e que pode refletir de forma substancial na vida dos discentes do Programa.

\section{RESULTADOS}

\section{Proposta de nova portaria conjunta SMASAN/SMED/SMATE}

Alterando alguns trechos do texto original e adicionando artigos, parágrafos e incisos, a 'nova portaria' mantém a essência do Programa e propõe mudanças em dispositivos que desenvolverão os educandos em sua integralidade, facilitando assim o início no processo de empoderamento, assim como proposto por autores como Freire (1987), Gohn (2002), Carmo (2009), Rodrigues (2009), Lombardi (2010) e Ciavatta (2014). 


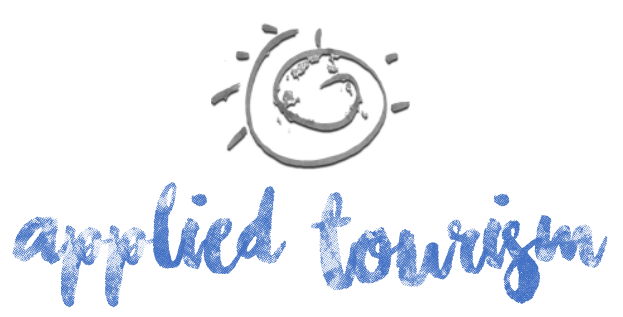

Volume 2, número 2, 2017, p. 56-77

(1990), Brasil (1996), Comerlatto et. al. (2007) e Brasil (2012) tais alterações facilitariam os processos de aprendizagem e efetividade do Programa no que se refere ao pleno desenvolvimento do educando.

Preconiza-se a criação do artigo $4^{\circ}$ (outrora omitido) que versa especificamente sobre o processo de formação. Sem entrar diretamente na dinâmica educativa - processo a ser desenvolvido por profissionais qualificados para tal - este momento apresenta os ideais centrais referentes à pesquisa. Aponta-se aqui a necessidade da implantação de uma educação libertária, empoderadora, vinculada ao mundo do trabalho e à sociedade. Por meio deste artigo estão estimulados:

- A formação integral dos sujeitos como potenciais atores para o desenvolvimento local (Prefeitura Municipal de Belo Horizonte, 1990; Brasil, 1996; Gallichio, 2002; Brasil, 2012);

- As discussões pertinentes ao momento atual da sociedade e utilização de metodologias ativas de aprendizagem (Barbosa\& Moura, 2013; Weinberg, 2014; Ottonelli, Viero \& Rocha, 2015);

- A apropriação de espaços comunitários (Perkins \& Zimmerman, 1995; UNDP, 2010; Borges \& Maschietto, 2014; Souza, Moreira\& Bourguignon, 2014).

Sugere-se por fim adequações aos incisos IX do artigo $5^{\circ}$ e inciso VII do artigo $6^{\circ}$ no que se refere aos profissionais que lidarão diretamente com os discentes durante os cursos. Apoiado nos ideais da Lei de Diretrizes e Bases (Brasil, 1996), indica-se a alocação de profissionais específicos para as habilidades exigidas, que tenham domínio dos conteúdos para articulá-los no projeto interdisciplinar, além de oferecer processos de educação continuada para tais professores/educadores.

Para facilitar a visualização das propostas da referida portaria apresenta-se no quadro abaixo (Quadro 1) o comparativo entre as portarias - vigente e nova - desenvolvida pelo autor da pesquisa. 


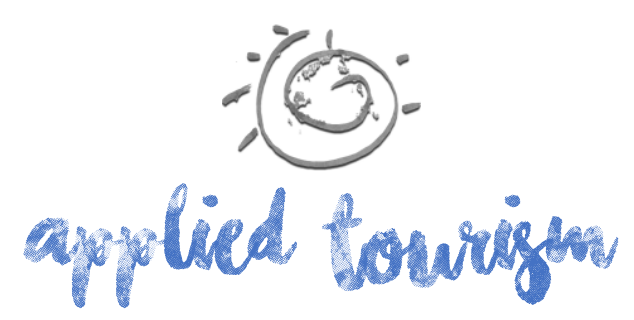

Volume 2, número 2, 2017, p. 56-77

QUADRO 1 - Comparativo das portarias municipais

\begin{tabular}{|c|c|}
\hline \multicolumn{2}{|c|}{ Quadro comparativo entre as portarias conjuntas SMED/SMASAN/SMATE } \\
\hline Portaria vigente №001/2011 & Portaria proposta \\
\hline \multicolumn{2}{|c|}{ Artigo 1으 } \\
\hline $\begin{array}{l}\text { Propõe a realização de cursos de } \\
\text { qualificação para alunos da RME acima de } \\
16 \text { anos no Mercado da Lagoinha }\end{array}$ & Institui o Programa Pão Escola na PBH \\
\hline \multicolumn{2}{|c|}{ Artigo 2으 } \\
\hline $\begin{array}{l}\text { Definir atribuições que visam a garantir a } \\
\text { efetividade da parceria }\end{array}$ & $\begin{array}{l}\text { Propõe a realização de cursos de } \\
\text { qualificação profissional para alunos da } \\
\text { RME acima de } 15 \text { anos no Mercado da } \\
\text { Lagoinha e apresenta os objetivos do } \\
\text { Programa }\end{array}$ \\
\hline \multicolumn{2}{|r|}{ Artigo 3은 } \\
\hline Apresenta as atribuições da SMASAN & $\begin{array}{l}\text { Propõe a criação de uma equipe } \\
\text { intersetorial que irá lidar com o } \\
\text { desenvolvimento e manutenção contínua } \\
\text { do Programa }\end{array}$ \\
\hline \multicolumn{2}{|r|}{ Artigo 4은 } \\
\hline Apresenta as atribuições da SMED & $\begin{array}{l}\text { Propõe os requisitos básicos para o } \\
\text { processo de formação }\end{array}$ \\
\hline \multicolumn{2}{|r|}{ Artigo 5인 } \\
\hline Apresenta as atribuições da SMATE & Apresenta as atribuições da SMASAN \\
\hline \multicolumn{2}{|c|}{ Artigo 6은 } \\
\hline Refere-se à publicação e vigor da portaria & Apresenta as atribuições da SMED \\
\hline \multicolumn{2}{|c|}{ Artigo 70 } \\
\hline- & Apresenta as atribuições da SMATE \\
\hline \multicolumn{2}{|c|}{ Artigo 80} \\
\hline- & $\begin{array}{l}\text { Refere-se à publicação e vigência da } \\
\text { portaria }\end{array}$ \\
\hline
\end{tabular}

Fonte: autor, 2017.

Por meio deste comparativo é possível visualizar de uma forma mais compacta a alteração do artigo $1^{\circ}$ e a criação de dois novos artigos, os quais versam diretamente sobre a equipe intersetorial e a formação que deve ser destinada aos alunos com um formato mais dinâmico e interdisciplinar.

\section{Aplicabilidade da nova portaria e prováveis reflexos}

Considerando-se que a sociedade é estruturada em torno do trabalho, faz-se necessário entender as situações atuais as quais os trabalhadores estão vivendo e os prováveis reflexos que pequenas mudanças poderiam impactar nas vidas dos mesmos, bem como no mercado 


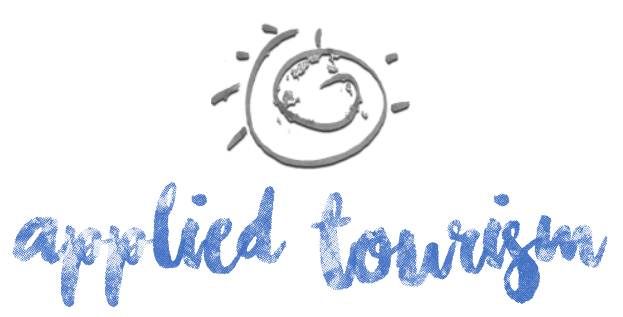

Volume 2, número 2, 2017, p. 56-77

e na sociedade. É importante ver ainda que o trabalho é fator preponderante para o crescimento da sociedade e, consequentemente, poderia ser uma força motriz para o desenvolvimento, entendendo-se assim a importância de apresentar a relevância da relação entre o trabalho e a educação, e seus impactos na sociedade.

Estabelecidos em uma sociedade capitalista, é de fundamental importância que o trabalhador busque com frequência novas atualizações e formações para atuação no mundo do trabalho, uma vez que, segundo Rocha-Vidigal \& Vidigal (2012) as empresas exigem, na atualidade, novos níveis de produtividade. Os sujeitos devem, portanto, se adequarem às novas demandas que vem do mercado e do capital (Carmo, 2015).

Alguns dos requisitos que se tornaram básicos ao trabalhador são, por exemplo, a autoaprendizagem, o entendimento de processos, a noção da observação, a interpretação, a tomada de decisão e a avaliação dos resultados (Rocha-Vidigal \& Vidigal,2012). Alves \& Vieira (1995) corroboram este ideal afirmando ser essencial o domínio da linguagem técnica, a comunicação oral, a escrita, a habilidade dos trabalhos em grupo, a polivalência cognitiva e a versatilidade organizacional.

A EP é vista como uma forma de qualificação que poderia auxiliar os trabalhadores dentro deste processo de formação e entendimento de suas atribuições e competências (Steffen \& Fischer, 2008). É fundamental, porém, reforçar que, para que tais efeitos sejam visíveis nos sujeitos o processo formativo deveria estimulá-los em todas as suas áreas e potencialidades (Carmo, 2015). Como apresentado por Marx (1983), Baquero (2012), Ciavatta (2014) e Machado (2015), o sujeito que é incitado em várias áreas e participa de um processo dinâmico de aprendizagem, poderia ter reforçada a sua integralidade humana e desenvolver várias habilidades as quais seriam projetadas de forma benéfica para o mundo do trabalho e para a comunidade.

Entende-se com o exposto acima e, apoiado nos estudos dos autores trazidos anteriormente, que com a implementação das alterações aqui propostas, os discentes que 


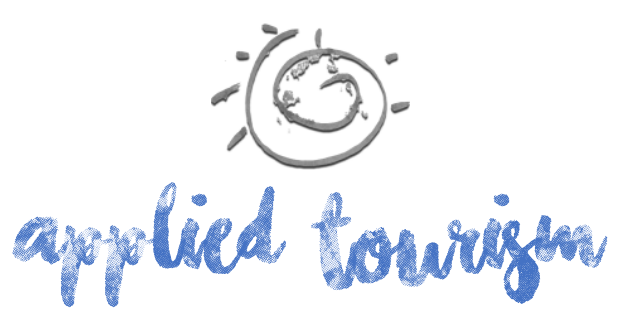

Volume 2, número 2, 2017, p. 56-77

mercado. Com uma portaria extremamente enxuta que não engloba princípios fundamentais para o desenvolvimento dos cursos, este Programa atua de forma pontual na oferta de qualificação para determinado público que, muitas vezes, ao menos se insere no mundo do trabalho.

Com a proposta inovadora de alterar tópicos em execução e inserir conceitos que muitas vezes já estão preconizados nas próprias legislações federais e até mesmo municipais, a orientação de alterar a portaria municipal em vigor ambicionou inserir princípios básicos garantidos por lei no que tange à formação integral dos sujeitos como cidadãos dotados de direitos e deveres. As observações levantadas e comentadas ao longo deste artigo evidenciam a necessidade de se alterar algo que está posto, em prol de uma melhora dos serviços prestados à população que muitas vezes fica à margem de vários benefícios sociais intrínsecos a todos os seres dentro de uma sociedade.

Remodelar tal dispositivo legal traria benefícios que, se verdadeiramente bem executados, facilitariam os processos de formação dos sujeitos e ofertaria a eles benefícios variados trazidos ao longo da literatura apresentada. Ampliar a visão de mundo, torná-los sujeitos críticos, decididos, independentes, proativos, os levaria a entrar no processo de empoderamento individual que traria, por consequência, melhoras em variados campos de suas vidas e da localidade a qual os sujeitos estão inseridos.

Alcançando seu objetivo, este estudo propôs uma nova formulação ao Programa, embasada em princípios humanos que objetivam desenvolver os sujeitos em sua totalidade para impulsionar, por consequência, o desenvolvimento local. Entende-se que essa proposição tem por limitação a baixa quantidade de normatizações legais no que se refere à educação profissional - objeto deste estudo. Indica-se que outros pesquisadores busquem dar continuidade a esta pesquisa levando adiante as análises sobre o referido Programa primordialmente se houver a devolutiva positiva da $\mathrm{PBH}$ na implementação do produto desenvolvido. É de fundamental importância entender os impactos resultantes da referida sugestão apresentada. 


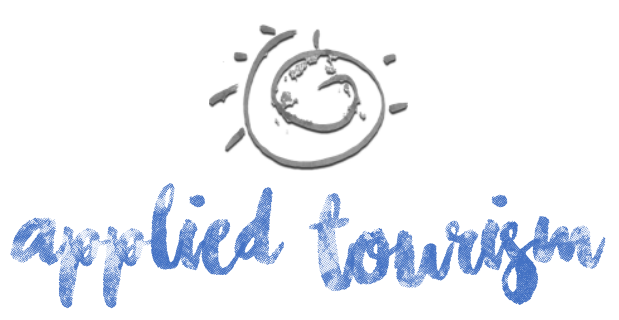

Volume 2, número 2, 2017, p. 56-77

Ciavatta, M. (2014). O ensino integrado, a politecnia e a educação omnilateral. Por que lutamos? Trabalho \& Educação. v.23, n.1, 187-205.

Comerlatto, D. et. al.(2007). Gestão de políticas públicas e intersetorialidade: diálogo e construções essenciais para os conselhos municipais. Katálisys, Florianópolis, v.10, n. 2, 265-271.

Dias, F. D., Machado, L. R. S. \& Figueiredo, F. C. (2016). A Dualidade do Sistema Educacional e a Educação Profissional à Luz da Divisão do Trabalho em MarxIn: Simpósio Nacional Educação, Marxismo e Socialismo, 1, 2016, Belo Horizonte. Anais. Belo Horizonte.

Figueiredo, A. C. \& Mueller, R. R. (2015).A política de educação profissional e tecnológica: uma análise do Programa Nacional de Acesso ao Ensino Técnico e Emprego (PRONATEC). $3^{\circ}$ Encontro Internacional de Política Social e $10^{\circ}$ Encontro Nacional de Política Social. Vitória: [s.n.].

Freire, P. (1987). Pedagogia do oprimido. Rio de Janeiro: Paz e Terra.

Frigotto, G. (2013). Ensino médio e técnico profissional: disputa de concepções e precariedade. Le Monde Diplomatique Brasil, São Paulo, v.6, n.68, 28-29. Recuperado em 16 maio, 2016, de http://www.diplomatique.org.br/artigo.php?id=1384.

Gallichio, E. (2002) Empoderamento, teorias de desenvolvimento e desenvolvimento local na América Latina. In: ROMANO, Jorge O.; ANTUNES, Marta (Org.). Empoderamento e direitos no combate à pobreza. Rio de Janeiro: ActionAid Brasil.

Gohn, M. G. (2002). Educação popular na América Latina no novo milênio: impactos do novo paradigma. ETD-Educação Temática Digital, Campinas, v. 4, n. 1, 53-77.

Horochovski, R. R. \& Meirelles, G. (2007). Problematizando o conceito de empoderamento. In: Seminário Nacional Movimentos Sociais, Participação e Democracia, 2, 2007, Florianópolis. Anais: II Seminário Nacional Movimentos Sociais, Participação e Democracia, Florianópolis, UFSC.

Inojosa, R. M. (2001). Sinergia em políticas e serviços públicos: desenvolvimento social com intersetorialidade. Cadernos FUNDAP, LOCAL, n 22, 102-110.

Kiss, L. B., Schraiber, L. B. \& D'oliveira, A. F. P. L. (2007). Possibilidades de uma rede intersetorial de atendimento a mulheres em situação de violência. Interfae - Comunicação, Saúde e Educação, LOCAL, v. 11, n. 23, 485-501.

Kleba, M. E. \&Wendausen, A. (2009). Empoderamento: processo de fortalecimento dos sujeitos nos espaços de participação social e democratização política. Saúde e Sociedade. São Paulo, v.18, n. $4,733-743$.

Lombardi, J. C. (2010). Reflexões sobre educação e ensino na obra de Marx e Engels. Campinas, SP: Tese (livre docência) - Universidade Estadual de Campinas, Faculdade de Educação, [s.n.].

Lopes, T. H. (2016). O uso de aplicativos em dispositivos móveis como ferramentas para o ensino de práticas gastronômicas: uma proposta de dinâmica no processo de ensino-aprendizagem da gastronomia. Applied Tourism, 1(1), 25-46. 


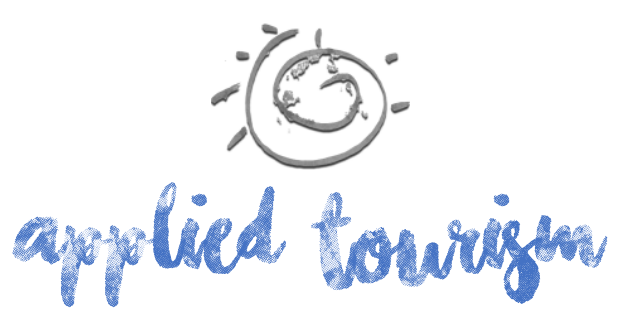

Volume 2, número 2, 2017, p. 56-77

Machado, L. R.S. (2015). Processos Pedagógicos na Educação Profissional e Tecnológica. 2015. In: BIAGINI, Jussara; VASCONCELOS, Fernanda. Educação profissional: formação, valorização e trabalho docente. Belo Horizonte. 14-39.

Mangini, F. N. R. \& Mioto, R.C. T. (2007). A interdisciplinaridade na sua interface com o mercado de trabalho. Katálisys, Florianópolis, v. 12, n. 2, 207-215.

Marx, K. (1983). Contribuição à Crítica da Economia Política. São Paulo: Martins Pontes.

Moura, D. H. (2007). Educação básica e educação profissional e tecnológica: dualidade histórica e perspectivas de integração. Holos, v. 2, 4-30.

Oliveira, J. M. \& Machado, L. R. S. (2012). Núcleo politécnico comum: concepções, diretrizes e desafios aos cursos técnicos. B. Téc. Senac: a R. Educ. Prof., v. 38, n. 3, 17-29.

Ottonelli, J., Viero, E. F. F. \& Rocha, K. M. (2015). Estudo de caso: metodologia de ensinoaprendizagem na Educação profissional. B. Tec. Senac, Rio de Janeiro, v. 41 n. 3, 54-69.

Perkins, D. \& Zimmerman, M. (2016). Empowerment Theory, Research and Application. Amerincan Journal of Community Psychology. v. 23, n. 5, 569-579. Recuperado em 4 agosto, 2016 de https://my.vanderbilt.edu/perkins/les/2011/09/empintro. proquest.pdf

Prefeitura Municipal de Belo Horizonte. (1990).Lei orgânica do município de Belo Horizonte. Belo Horizonte, MG.

Prefeitura Municipal De Belo Horizonte. (2011).Portaria conjunta SMED/SMASAN/SMATE $n^{0} 001 / 2011$.

Rocha-Vidigal, C. B. \& Vidigal, V. G. (2012). Investimento na qualificação profissional: uma abordagem econômica sobre sua importância. Acta Scientiarum. Human and Social Sciences, Maringá, v. 34, n. 1, 41-48.

Rodrigues, J. (2009). Dicionário da Educação Profissional em Saúde.

Schlesener, A. H. (2015). Marx e a educação: observações acerca da Ideologia Alemã e Teses contra Feuerbach. Germinal: Marxismo e Educação em Debate, Salvador, v. 7, n. 2, 163-175.

Souza, C. G., Moreira, D. \& Bourguignon, J. A. (2014). Aproximações entre participação e empoderamento em uma perspectiva emancipatória. Revista NUPEM, Campo Mourão, v. 6, n. 11.

Steffen, E. M. \& Fischer, M. C. B. (2008). Qualificação profissional do técnico industrial em plásticos. Cadernos de Educação, Pelotas, nº 31, 227-248.

Thiesen, J. S. (2008). A interdisciplinaridade como um processo articulador do processo ensinoaprendizagem. Revista Brasileira de Educação, LOCAL, v. 13, n. 39, 545-598.

Tomé, A. C. A. (2012). Trabalho e/ou educação: história da educação profissional no Brasil. \#tear: Revista de Educação, Ciência e Tecnologia, Canoas, v. 1, nº 2 . 


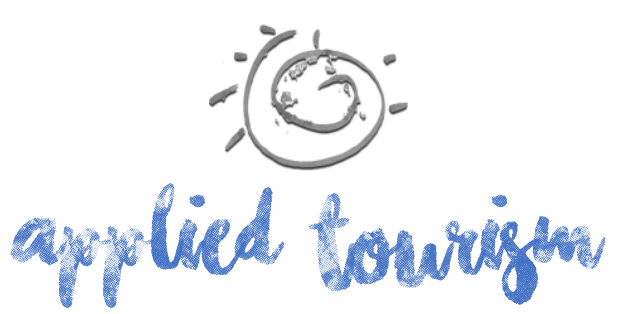

Volume 2, número 2, 2017, p. 56-77

UNDP. (2010). United Nations Development Programme, 2010. Human Development Report 2010. The Real Wealth of Nations: Pathways to Human Development. New York.

Weinberg, P.D. (2014). Educação Profissional: rompendo certezas, correndo fronteiras. B. Téc. Senac, Rio de Janeiro, v. 40, n. 2, 6-29. 